\title{
秎 \\ INCLUSÃO NO CONTEXTO ESCOLAR: PERCEPÇÕES DE ALUNOS COM DEFICIÊNCIA INTELECTUAL E PROFESSORES DE EDUCAÇÃO FÍSICA \\ INCLUSION IN THE SCHOOL CONTEXT: PERCEPTIONS OF STUDENTS WITH INTELLECTUAL DISABILITIES AND TEACHERS OF PHYSICAL EDUCATION
}

\section{INCLUSIÓN EN EL CONTEXTO ESCOLAR: PERCEPCIONES DE ALUMNOS CON DISCAPACIDAD INTELECTUAL Y PROFESORES DE EDUCACIÓN FÍSICA}

Fagner José Passos*

\begin{abstract}
Resumo: Esta pesquisa teve como objetivo comparar as percepções dos alunos com deficiência intelectual e professores de educação física relativamente à inclusão no contexto escolar. Trata-se de um estudo de caso de caráter qualitativo e delineamento transversal realizado em 2018. Participaram da pesquisa sete alunos e três professores de uma escola estadual de Monte Belo/MG. Foram realizadas entrevistas semiestruturadas, sendo as respostas processadas por meio da análise de similitude do software IRAMUTEQ. Os principais resultados apontam que tanto os alunos como os professores estão satisfeitos com o processo inclusivo da instituição de ensino em que atuam. Entre os aspectos apontados pelos participantes que confirmam uma escola inclusiva está a assiduidade, a participação, a relação aluno/aluno e professor/aluno, o local e a satisfação pelas aulas aplicadas. Conclui-se que o processo de inclusão dessa escola tem sido satisfatório na perspectiva do aluno e do professor.
\end{abstract}

Palavras-chave: Deficiência intelectual; educação física; inclusão escolar.

Abstract: This research aimed to compare the perceptions of students with intellectual disabilities and Physical Education teachers about inclusion in the school context. This is a case study of a qualitative nature and cross-sectional design carried out in 2018. Seven students and three teachers from a Monte Belo-MG State School participated in the study. Participants were interviewed through two scripts with 11 questions, and responses were processed through simulation analysis of the IRAMUTEQ software. In the results, both students and teachers point to the satisfaction of the inclusive process in the teaching institution they work in. Among the aspects that confirm an inclusive school is assiduity, participation, student / student and teacher / student relationship, location and satisfaction with the classes applied. It can be concluded that this institution of education develops the process of inclusion in a satisfactory way both from the perspective of the student and the teacher.

\footnotetext{
* Especialista em Práticas Pedagógicas pela Universidade Federal de Ouro Preto - MG/2014 e em Esportes e Atividades Físicas Inclusivas para Pessoas com Deficiência pela Universidade Federal de Juiz de Fora - MG/2018. (fagnerpassos88@gmail.com)
} 
Keywords: Intellectual disability, physical education, school inclusion.

Resumen: Esta investigación tuvo como objetivo comparar las percepciones de los alumnos con discapacidad intelectual y profesores de Educación Física sobre la inclusión en el contexto escolar. Se trata de un estudio de caso de carácter cualitativo y delineamiento transversal realizado en 2018. Participaron de la investigación 7 alumnos y 3 profesores de una Escuela Estadual de Monte Belo-MG. Se realizaron entrevistas semiestructuras, siendo las respuestas procesadas por medio del análisis de similitud del software IRAMUTEQ. Los principales resultados apuntan que tanto los alumnos como los profesores están satisfechos con el proceso inclusivo de la institución de enseñanza que actúan. Entre los aspectos señalados por los participantes que confirman una escuela inclusiva está la asiduidad, la participación, la relación alumno / alumno y profesor / alumno, el local y la satisfacción por las clases aplicadas. Se concluye que el proceso de inclusión de esta escuela ha sido satisfactorio en la perspectiva del alumno y del profesor.

Palabras clave: Deficiencia intelectual; educación física; inclusión escolar.

\section{Introdução}

Atualmente, o termo inclusão está em evidência em várias áreas de estudo, especialmente na educação. Antes era algo distante depararmo-nos com alunos com deficiências no ensino regular, porém, ultimamente, essa realidade é outra e afirma a importância da inclusão de todos os alunos no ambiente escolar.

De acordo com Freire (2008), a inclusão é um movimento educacional, social e político que vem defender o direito de todos os indivíduos de participarem, de forma consciente e responsável, na sociedade de que fazem parte e de serem aceitos e respeitados naquilo que os diferencia dos outros. Na educação, defende o direito de todos os alunos desenvolverem e concretizarem as suas potencialidades, apropriando competências que lhes permitam exercer o seu direito de cidadania, através de uma educação de qualidade planejada a partir das suas necessidades, interesses e características.

A inclusão educacional no Brasil é um direito do cidadão e é assegurada na legislação através de várias normas: a Constituição Federal (1988); a Lei 9.394, de Diretrizes e Bases da Educação, de 1996; a Declaração de Salamanca (1994); a Convenção da Organização das Nações Unidas (2006); a Lei N 10.098, de 19 de dezembro de 2000; a Lei n ${ }^{\circ} 13.146$, de 6 de julho de 2015; e o documento mais recente que foi integrado à educação - a nova Base Nacional Comum Curricular BNCC (2017) - que é uma ferramenta que norteia o ensino em todas as escolas do país, do ensino infantil ao ensino fundamental, em todas as fases de desenvolvimento do aluno.

Esses avanços que vêm sendo efetivados no decorrer dos anos mostram a importância da fase de inclusão educacional pela qual estamos passando e o quanto é essencial que as 
escolas e profissionais estejam preparados para atender essa demanda. De acordo com Barreto e Barreto (2016), a inclusão, diante de toda a teoria e leis, garante o direito à escola, mas, para isso acontecer na prática, é preciso ir além, é necessário ocorrer várias mudanças no que concerne à estrutura organizacional e física da escola, da sociedade e da comunidade escolar.

Quando se trata da inclusão escolar, as disciplinas curriculares apresentam ferramentas e instrumentos capazes de auxiliar o professor na aplicação de suas aulas; entre essas disciplinas está a educação física (EF). Para Betti e Zuliani (2002) a EF, enquanto componente curricular da educação básica, deve assumir a tarefa de introduzir e integrar o aluno na cultura corporal de movimento, formando o cidadão que vai produzi-la, reproduzi-la e transformá-la, instrumentalizando-a para usufruir do jogo, do esporte, das atividades rítmicas e dança, das ginásticas e práticas de aptidão física, em benefício da qualidade da vida.

Com o processo de inclusão surgiu também a educação física adaptada (EFA), que prevê a atuação do professor, com alunos com deficiência e com necessidades educacionais, compreendendo métodos para atendimento a esse público. Souza (2014) destaca que a EFA tem-se tornado uma importante mediadora para o processo de inclusão no universo de EF, cujo objetivo é o de possibilitar a difusão de fundamentos teórico-práticos dos vários conhecimentos que compõem a área de EF, desde a saúde e o lazer até a escola.

Enquanto conteúdo pedagógico, as práticas relacionadas à EF e EFA vivenciam a diversidade de movimentos e de possibilidades, que incluem alunos com e sem deficiência no mesmo ambiente. Para Daolio (2005), uma dificuldade nas aulas de EF é justamente essa: atingir todos os alunos ao mesmo tempo; entretanto, essas tensões ajudam as novas reflexões e devem ser cada vez mais discutidas e repensadas para a apresentação de uma educação para todos.

Embora a EF tenha tantos elementos para estudo, devemos também reconhecer a importância da comunidade escolar no processo de inclusão. É necessário destacar as percepções daqueles que já participam efetivamente desse processo de inclusão, por isso, entende-se que, ao averiguar e comparar as opiniões dos alunos com deficiência e dos professores de EF, tem-se a oportunidade de pontuar as principais dificuldades enfrentadas por essa população, podendo-se ainda sugerir mudanças nos elementos ressaltados de maneira a buscar a promoção de um ambiente efetivamente inclusivo para ambos os públicos.

No estudo de Alves e Duarte (2014) as percepções dos alunos com deficiência intelectual e a experiência subjetiva de inclusão estiveram associadas a três fatores: adaptação, participação social e capacidade. Nestes fatores apresentados, adaptação refere-se à adequação estrutural, pedagógica, metodológica e material para participação ativa na aula. A participação social se relaciona com a convivência do aluno com deficiência com seus pares na escola, associada à aceitação pelo grupo e a interação social com ele. E a capacidade, que é influenciada pelo sentimento de sentir-se capaz de realizar as atividades das aulas. Para os autores, a 
inclusão, nesses aspectos, deixa de ser um problema do professor para ser responsabilidade de todos.

Já quando as perspectivas vêm dos professores sobre a inclusão de alunos com deficiências nas aulas de EF, Gorgatti e Júnior (2009) destacam, em estudo, que os docentes declararam não estar preparados para lidar com alunos que apresentem deficiência, embora os professores com menor tempo de experiência mostraram-se mais otimistas ao movimento de inclusão. Nos resultados obtidos, os professores apontaram como dificuldade a falta de recursos materiais apropriados e de apoio multidisciplinar.

Considerando todos os aspectos colocados e o momento atual de inclusão na educação, torna-se necessário investigar as percepções das pessoas que participam diretamente desse processo, uma vez que suas opiniões são relevantes para avaliar, refletir e, se necessário, reformular o andamento de tal processo. A partir disso, esta pesquisa visa comparar as percepções dos alunos com deficiência intelectual e professores de EF sobre a inclusão no contexto escolar.

\section{Metodologia}

Trata-se de um estudo de caso de caráter qualitativo e delineamento transversal realizado entre junho e julho de 2018 com sete alunos (A1, A2, A3, A4, A5, A6 e A7), com deficiência intelectual (Quadro 1) e três professores (P1, P2 e P3) de educação física (Quadro 2) de uma escola estadual da cidade de Monte Belo, MG.

Para Fonseca (2002), o estudo de caso pode ser caracterizado como um estudo de uma entidade bem definida, de um sistema educativo, uma pessoa, evidenciando a sua unidade e identidade própria. É uma investigação sobre uma situação específica que se supõe ser única em muitos aspectos.

A escolha pelo tipo de pesquisa reforça, de acordo com André (2013), uma perspectiva que concebe o conhecimento como um processo socialmente construído pelos sujeitos nas suas interações frequentes, enquanto atuam na realidade transformando-a e sendo por ela transformados. Tal pesquisa preocupa-se com aspectos da realidade que não podem ser quantificados, centrando-se na compreensão e explicação da dinâmica das relações sociais.

Bastos e Duquia (2007) enaltecem que a condução de um estudo transversal envolve três etapas: a definição de uma população de interesse; o estudo da população por meio da realização de amostragem de parte dela; e a determinação da presença ou ausência do desfecho e da exposição para cada um dos indivíduos estudados.

Devido à especificidade da população da presente pesquisa, foram estabelecidos dois critérios de inclusão. Primeiramente, foi delimitado que, dentre as escolas públicas e regulares de Monte Belo, seria selecionada a instituição que obtivesse a maior quantidade do público em questão, ou seja, alunos com deficiência intelectual, sendo estes atendidos por professores de 
educação física. Além disso, foi definido que só seriam inclusos no estudo os participantes que assinassem o Termo de Consentimento Livre e Esclarecido.

Sobre os instrumentos utilizados, o pesquisador deste trabalho elaborou dois roteiros de entrevista: um para os alunos com deficiência e outro para os professores de educação física. As entrevistas foram realizadas de maneira individual nas dependências da escola. Ressalta-se que ambos os roteiros são semelhantes, compostos por 11 questões que visavam avaliar os aspectos afetivos, pedagógicos, sociais e arquitetônicos relacionados à percepção dos alunos com deficiência intelectual e dos professores de EF com relação ao processo de inclusão.

Após a realização das entrevistas, elas foram transcritas e transformadas em dois corpi textuais (um com as respostas dos alunos com DI e outro com as dos professores de EF) para que se desse início às análises. Para apoiar a análise dos dados desta pesquisa, utilizou-se a análise de similitude do software IRAMUTEQ (Interface de $\mathrm{R}$ pour les Analyses Multidimensionnelles de Textes et de Questionnaires). Este software permite fazer diferentes processamentos e análises estatísticas de textos produzidos. O mesmo é ancorado no software $\mathrm{R}$ e na linguagem de programação python.

\begin{abstract}
A análise de similitude se baseia na teoria dos grafos, possibilita identificar as coocorrências entre as palavras e seu resultado traz indicações da conexidade entre as palavras, auxiliando na identificação da estrutura de um corpus textual, distinguindo também as partes comuns e as especificidades em função das variáveis ilustrativas (descritivas) identificadas na análise (MARCHAND; RATINAUD, 2012 Apud CAMARGO; JUSTO, 2013).
\end{abstract}

O software não é um método de análise de dados, mas uma ferramenta para processálos, portanto não descarta a interpretação do pesquisador, que é essencial para a pesquisa.

\title{
3 Resultados e discussões
}

Pode-se observar no Quadro 1 a caracterização dos alunos com deficiência intelectual participantes do estudo. Sublinha-se que a idade dos participantes é de 21,71 $\pm 10,24$ anos, sendo que $71,4 \%(n=5)$ dos discentes são do sexo masculino. Além disso, aponta-se que 42,8\% $(n=3)$ dos alunos frequentam a educação de jovens e adultos (EJA) e outros 42,8\% (n=3), o ensino fundamental.

A partir dos dados de caracterização, confirmamos a inserção dos alunos com deficiência nos mais variados níveis de ensino. Laplane (2015) também confirma essa variação através dos documentos norteadores da política educacional. A presença desses alunos em todos os níveis e etapas do ensino é um fato consumado na educação básica no Brasil. 
Quadro 1 - Caracterização dos alunos quanto ao sexo, idade, ano escolar e deficiência

\begin{tabular}{|c|c|c|c|c|}
\hline Pseudônimo & Sexo & Idade & Ano Escolar & Deficiência \\
\hline A1 & Masculino & 43 & EJA & DI \\
\hline A2 & Feminino & 21 & EJA & DI \\
\hline A3 & Masculino & 24 & $1^{\mathbf{0}}$ Ano - Ensino médio & DI \\
\hline A4 & Masculino & 16 & $6^{\mathbf{0}}$ ano - Ensino fundamental & DI \\
\hline A5 & Masculino & 12 & $8^{\mathbf{0}}$ Ano - Ensino fundamental & DI \\
\hline A6 & Masculino & 14 & $9^{\mathbf{0}}$ Ano - Ensino fundamental & DI \\
\hline A7 & Feminino & 16 & &
\end{tabular}

Fonte: Dados da pesquisa. Monte Belo, MG, 2018.

Já no Quadro 2 pode-se averiguar a caracterização dos professores de EF. A idade média do grupo é de 43,33 $\pm 14,46$ anos, sendo que $66,6 \%(n=2)$ são do sexo feminino. Ademais, pode-se observar que, dos professores que já atuam a mais tempo na docência, $66,6 \%$ $(n=2)$ já realizaram cursos de capacitação na área de inclusão.

A capacitação profissional é extremamente importante, pois retrata a segurança das ações promovidas pelo professor nas aulas. Segundo Farias (2003, apud GORGATTI E JÚNIOR, 2009), esse aprimoramento é um fator que certificará o progresso, a qualidade e a manutenção de todos os alunos na escola; afinal, o professor terá a competência para avaliar qual tipo de intervenção vai favorecer o desenvolvimento dos alunos, o impacto da inclusão para os alunos sem deficiência, se há modificação no desempenho da aprendizagem e como esse desempenho pode ser potencializado.

Quadro 2 - Caracterização dos professores quanto ao sexo, idade, tempo de atuação e capacitação

\begin{tabular}{|c|c|c|c|c|}
\hline Pseudônimo & Sexo & Idade & Tempo de atuação & $\begin{array}{c}\text { Possui capacitação na } \\
\text { área de inclusão }\end{array}$ \\
\hline P1 & Feminino & 36 & 4 anos e 6 meses & Não \\
\hline P2 & Masculino & 34 & 12 anos & Sim, cursos. \\
\hline P3 & Feminino & 60 & 42 anos & Sim, cursos. \\
\hline
\end{tabular}

Fonte: Dados da pesquisa. Monte Belo, MG, 2018.

A partir das respostas (corpus) dos alunos com deficiência intelectual, nota-se, conforme a Figura 1, a percepção dos participantes, que foi estruturada através da identificação das ocorrências entre as palavras e as indicações da conexidade entre os termos usados. Observa-se na figura a ocorrência de um leque semântico de palavras mais frequentes, que foram: "sim", "gosto", "participar", "não" e "bom". 


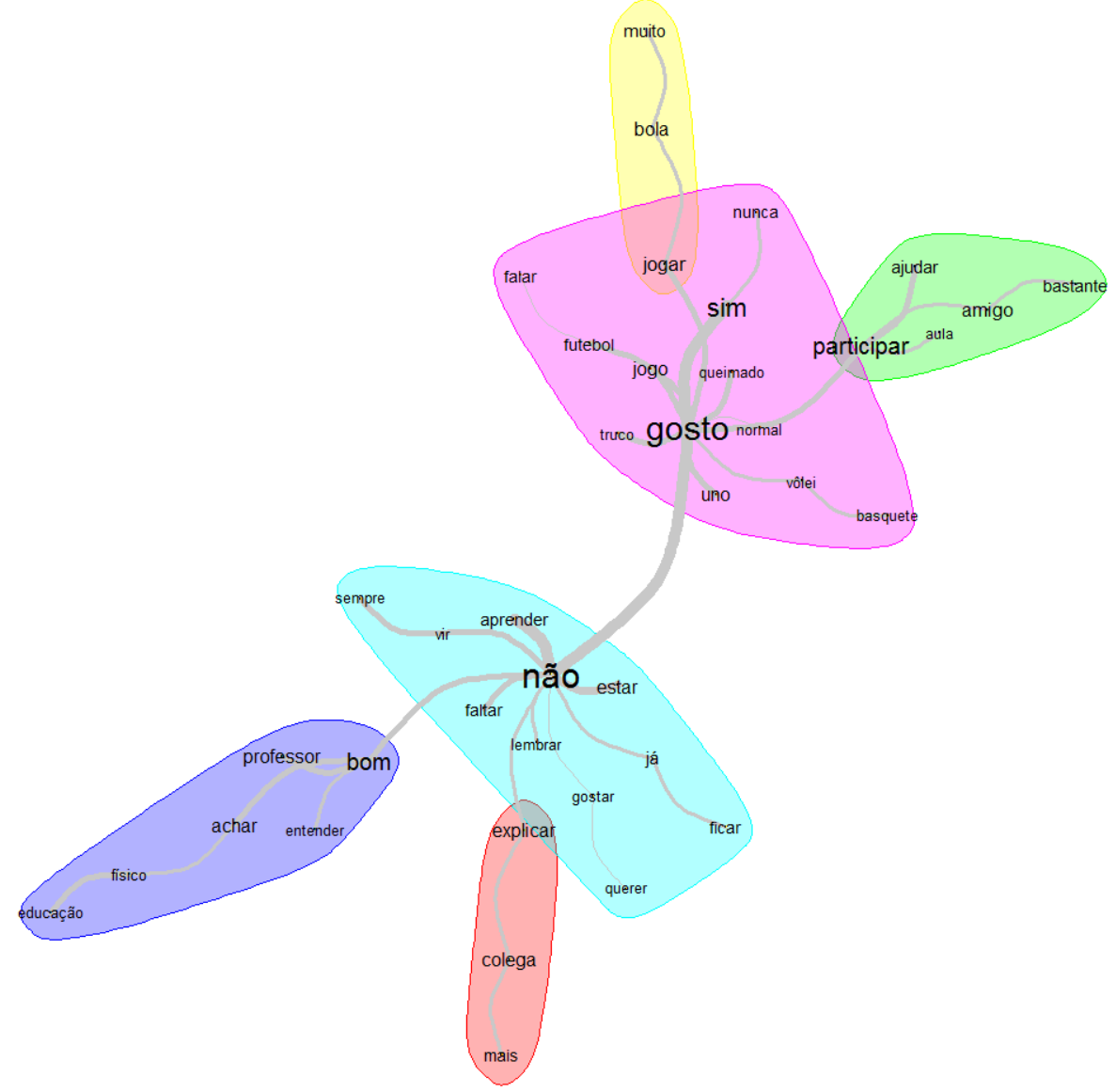

Figura 1. Percepção dos alunos com DI sobre o processo de inclusão no contexto escolar. Análise de similitude realizada com o software IRAMUTEQ.

Fonte: Dados da pesquisa. Monte Belo, MG, 2018.

Após a análise genérica da árvore de similitudes de ocorrência e respaldados nas respostas das entrevistas, podemos considerar que "sim", "gosto" e "participar" correspondem a aceitação, participação e a satisfação em realizar as atividades propostas nas aulas de EF pelos alunos com DI.

Referindo-se à a participação nas aulas, o aluno A6 declara: "Participo de todas". Em questão de aceitação e satisfação, a aluna A7 revela: "Gosto bastante."

Essa "simpatia" pela disciplina que é demonstrada pelos alunos nas respostas vai ao encontro do que é apresentado por Silva (2014), em que o autor conclui que os níveis de satisfação nas aulas de EF estão diretamente relacionados com o ambiente das aulas, a originalidade e diversidade das ações e com a habilidade com que os alunos realizam as atividades propostas pelo professor durante a disciplina em questão.

A conexão da palavra "não" se relaciona nas respostas com a boa frequência dos alunos e também com o fato de não encontrarem nenhuma dificuldade no espaço oferecido para as atividades da EF.

Nas respostas, o aluno A1 fala de sua assiduidade: "Eu não falto; apenas por 
necessidade, como não estar muito bem de saúde". O aluno A4 também comenta sobre sua frequência: "Eu participo de todas as aulas. Nunca faltei à aula." Sobre o espaço oferecido para a EF, a aluna A7 é categórica e responde: "Não precisa melhorar nada - está bom". A aluna A2 também responde satisfatoriamente sobre o local das aulas: "Eu gosto da escola. Eu gosto de tudo aqui."

Isso mostra que estar presente às aulas e aproveitar o que é oferecido pelo professor é essencial para uma aprendizagem. Ensinar e aprender em um ambiente apropriado é a garantia desse desenvolvimento. Para Freitas (2014), a organização do espaço escolar e seus desdobramentos para o ensino da EF de qualidade é de suma importância e tem influência direta na dinâmica das aulas, sendo que, se os espaços físicos escolares não atendem às necessidades dos alunos, as aulas tendem a se tornar desmotivadoras.

Já ao analisar a comunidade do termo "bom", esta reflete a relação do aluno com o professor e sua avaliação sobre as ações do docente em aula, bem como suas preferências e rejeições relacionadas aos conteúdos aplicados.

Nas respostas sobre a relação aluno/professor, o aluno A3 destaca a sua boa convivência: "Com a professora eu converso bastante. Eu gosto dela, ela é boa". O aluno A4 destaca a longevidade da relação com a docente: "Sim, gosto dela. Ela é minha professora desde o $5^{\circ}$ ano."

Acreditar em uma relação de confiança e respeito entre aluno e professor é um fator determinante para um bom convívio. Félix (2012) destaca a importância do diálogo e do equilíbrio na convivência durante as aulas de EF, nas quais a interação de ambas as partes traz consigo o desenvolvimento no processo de ensino e aprendizagem.

Também nas colocações sobre o "bom", temos as ramificações ligadas à aplicação de conteúdo que foi compreendido, com relação ao qual os alunos declararam suas preferências e rejeições. Nas opiniões, observamos a preferência da prática esportiva como conteúdo mais aprendido pelos alunos, como o futebol, vôlei e basquete, além de rejeição, como é o caso do handebol. É o que confirmamos nas respostas dos alunos A3 e A4, respectivamente: "Gosto de uno, corrida e esporte com bola. Gosto de futebol, vôlei, queimada e basquete. Eu acho chato na educação física é pular corda, e gincana também é ruim". "Gosto de futebol. Nas aulas de educação física, eu não gosto de handebol; eu acho chato."

Nas respostas dos alunos com DI, o esporte aparece como preferência nas atividades de EF, denotando que o ensino do conteúdo foi aprendido. Portanto, sua aplicabilidade deve permanecer no ambiente escolar, sendo que o professor deve se atentar às possíveis adaptações que são necessárias embasadas na EFA. Ribeiro (2009), em sua pesquisa, destaca que a inserção do esporte adaptado significa seguir um princípio importante na inclusão - a democracia. Ela concede aos alunos com deficiências a oportunidade de vivenciar as mesmas experiências que os demais. Mesmo que essas experiências lhes tragam a frustração de não ter obtido êxito, na 
continuidade o professor de EF poderá refletir juntamente com o aluno se ele se esforçou como poderia ou não. Tal experiência trará subsídios importantes na formação do aluno que repercutirão em outros momentos de sua vida, o que constitui mais um aspecto que reforça a importância da aplicação do conteúdo "esporte" no ambiente escolar.

Quando se fala em adaptações, Alves e Duarte (2014) destacam a necessidade de o aluno com deficiência sentir-se socialmente incluso no grupo ao qual pertence. Isso permite a estruturação do sentimento de pertencimento, essencial para se sentir incluído.

Essa sensação é colocada em evidência a partir da relação aluno/aluno, como é destacado pela discente A2: "Eles participam comigo, eles me ajudam, me explicam. Tenho muitos amigos na minha sala."

Ao analisar as respostas dos alunos, fica claro sua aceitação das aulas de EF que são oferecidas, sendo que não houve relatos que tirassem a objetividade de inclusão nesse ambiente. Mesmo que em suas colocações apareçam preferências e rejeições nas aulas, todos responderam satisfatoriamente ao movimento de inclusão, o que confirma que a EF vem sendo um instrumento fundamental para a educação inclusiva.

Já ao apresentar a análise de similitudes de ocorrência das respostas dos professores de EF, expostas na Figura 2, pode-se perceber a conexão entre os termos "não", "aluno", "deficiência", "participar", "atividade", "sim" e "gostar".

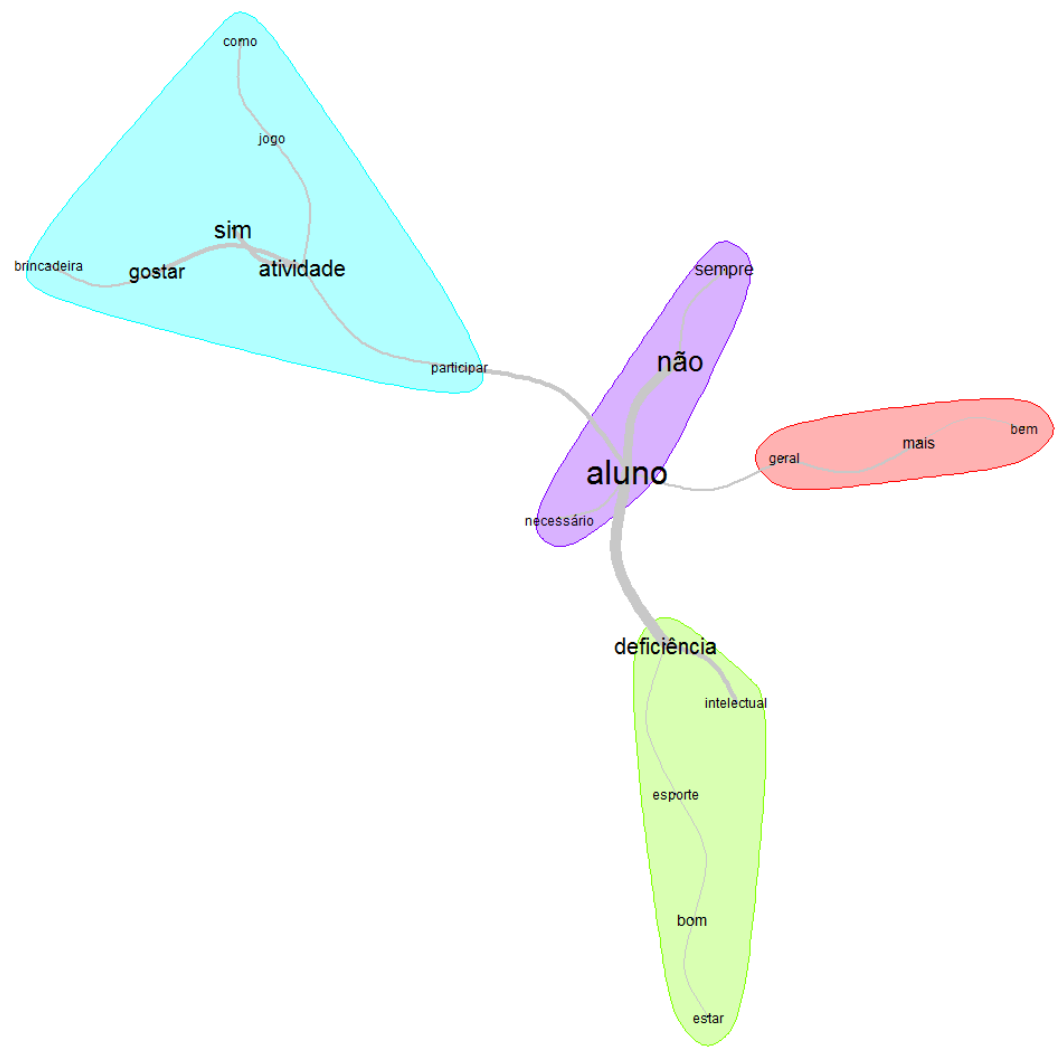

Figura 2. Percepção dos professores de EFI relativamente ao processo de inclusão no contexto escolar. Análise de similitude realizada com o software IRAMUTEQ.

Fonte: Dados da pesquisa. Monte Belo, MG, 2018. 
A partir da entrevista com os docentes, podemos considerar que o "não" confirma a boa frequência dos alunos nas aulas, além de comprovar que o espaço usado na EF corresponde às expectativas dos professores, que não encontraram dificuldades na aplicação das aulas aos alunos com DI.

Em suas colocações, os professores P1 e P2 confirmam a boa presença dos alunos: "A frequência é muito boa"; "São frequentes, não faltam." A respeito do local disponibilizado - se apresenta ou não dificuldades para o aluno com DI -, a professora P3 responde: "Não, o local oferecido é adequado para os alunos com deficiência."

É evidente que a presença dos alunos com DI nas aulas traz inúmeros benefícios, uma vez que conseguirão seguir uma ordem sequencial, estruturada e pedagógica do conteúdo aplicado pelo professor; além disso, a interação social será favorecida. Segundo Batista e Enumo (2004), muitas dificuldades de relacionamento entre colegas estão no fator tempo de exposição desses alunos a situações mais complexas, onde a baixa assiduidade reforça as diferenças existentes entre eles.

A conexão entre "aluno" e "deficiência" surgiu com frequência, pois corresponde ao foco da pesquisa, como é apontado pela professora P3 quando menciona a interação entre os colegas: "Os alunos que não têm deficiência ajudam sempre os com deficiência. São muito amorosos."

Os dados de matrícula escolar de alunos com deficiência e necessidades especiais, relatados por Laplane (2014), além de ser uma temática em evidência devido ao aumento de alunos com deficiência no ensino regular, indicam um aumento progressivo do atendimento na rede de educação básica no país, porém a distribuição dos alunos entre os níveis de ensino expõe um quadro que, ainda, prima pela desigualdade. A autora destaca a necessidade de a rede pública se estruturar de tal forma que garanta não apenas a matrícula, mas uma educação de qualidade, fornecendo aos alunos as ferramentas necessárias para a progressão no sistema.

Em relação às conexões entre "participar", "atividade", "sim" e "gostar", todas confirmam, nas respostas dos professores, o que também foi apresentado pelos alunos, em que "participar" e "atividade" se relacionam com a participação dos alunos com DI nas aulas e com a colaboração dos demais colegas de classe e do professor nas atividades propostas.

Em sua resposta, o professor P2 destaca a participação dos estudantes: "Os alunos participam de todas as atividades; ainda não demonstraram insatisfação com nenhuma atividade." Na afinidade entre aluno/aluno, a professora P1 responde:

(...) segundo o pouco que observo, são tratados de maneira igual. Cada um com sua particularidade. Não existe preconceito por parte dos alunos sem deficiência. O que eu noto é que os alunos com DI têm um certo medo de entrar em contato direto com os outros. 
Com relação à afinidade entre professor/aluno, a professora P3 relata sua experiência: "Já tive mais dificuldades, mas atualmente me relaciono bem com bastante facilidade."

Para uma inclusão na EF é necessário ir além da participação nas aulas, é preciso a interação entre os colegas. Como é apontado por Alves e Duarte (2014), a inclusão é dependente da qualidade das interações sociais estruturadas, em que estas devem ser positivas e permitir que o aluno se sinta aceito, reconhecido por sua capacidade de desempenhar um papel importante no grupo.

No que tange às conexões de "sim" e "gostar", estas demonstram, no entendimento dos professores, de forma unânime, a satisfação e a alegria dos alunos em relação aos conteúdos de EF aplicados, como esportes, jogos de raciocínio e brincadeiras. Para Shigunov (1993 apud SILVA, 2014), o gosto dos alunos e a satisfação pela EF recebe influência das características e intervenção pedagógica dos professores, sendo que a satisfação na EF pode ser vista como uma evolução geral do desenvolvimento do aluno.

A partir do disposto, pode-se evidenciar a colaboração desses personagens no processo de inclusão da referida escola, onde nenhuma dificuldade por partes dos professores foi colocada à mostra, apresentando o desenvolvimento de um trabalho satisfatório, capaz de atender as necessidades de alunos com e sem deficiência.

\section{Conclusão}

A partir dos resultados, ao comparar as percepções dos alunos com deficiência intelectual e professores de educação física de uma escola estadual em Monte Belo, MG, notase a semelhança nas respostas dos entrevistados, as quais apontam um olhar satisfatório de inclusão na escola em que atuam.

Entre os fatores que tornam a escola inclusiva estão: assiduidade, participação nas atividades, relação aluno/aluno e professor/aluno, local adequado para as atividades e satisfação pelas aulas de educação Física declarados pelos alunos e comprovados pelos professores.

Os resultados aqui descritos trazem à tona a realidade da inclusão no ambiente escolar de uma localidade. Sugere-se que novos estudos sejam feitos para compreender todos os aspectos de inclusão e ampliar a reflexão sobre o tema.

Para que o processo de inclusão ocorra e se desenvolva com efetividade, é preciso que professores, alunos, escola e sociedade deem sua contribuição. É necessário analisar a perspectiva de todos os integrantes sobre o desenvolvimento das ações que visam tal objetivo de maneira a avaliar e refletir sobre o andamento desse processo que ainda se encontra imaturo no ambiente escolar. Acredita-se que a inclusão é uma oportunidade para que todos participem da construção de uma sociedade mais justa e igualitária. 


\section{Referências}

ANDRÉ, Marli. O que é um estudo de caso qualitativo em educacão? Educação e Contemporaneidade, Salvador, v. 22, n. 40, p.95-103, dez. 2013. Disponível em: <http://www.revistas.uneb.br/index.php/faeeba/article/view/753/526>. Acesso em: 26 jul. 2018.

ALVES, Maria Luiza Tanure; DUARTE, Edison. A percepção dos alunos com deficiência sobre a sua inclusão nas aulas de Educação Física escolar: um estudo de caso. Revista Brasileira de Educação Física e Esporte, [s.1.], v. 28, n. 2, p.329-338, abr. 2014. FapUNIFESP (SciELO). http://dx.doi.org/10.1590/1807-55092014000200329.

BARRETO, Kelly Coelho Costa; BARRETO, Weslley Pinheiro. A Formação dos Professores e a Inclusão Escolar. Ciclo Revista, Goiânia, v. 2, n. 1, 2016. Disponível em: <https://www.ifgoiano.edu.br/periodicos/index.php/ciclo/article/view/211/124>. Acesso em: 18 jul. 2018 .

BASTOS, João Luiz Dornelles; DUQUIA, Rodrigo Pereira. Um dos delineamentos mais empregados em epidemiologia: estudo transversal. Scientia Medica, Porto Alegre, v. 7, n. 4, p.229-232, dez. 2007.

BATISTA, Marcus Welby; ENUMO, Sônia Regina Fiorim. Inclusão escolar e deficiência mental: análise da interação social entre companheiros. Estudos de Psicologia (natal), [s.l.], v. 9, n. 1, p.101-111, abr. 2004. FapUNIFESP (SciELO). http://dx.doi.org/10.1590/s1413$294 \times 2004000100012$.

BETTI, Mauro; ZULIANI, Luiz Roberto. Educação Física Escolar: Uma Proposta de Diretrizes Pedagógicas. Mackenzie de Educação Física e Esporte, Bauru, v. 1, n. 1, p.73-81, jan. 2002. Disponível em: <http://editorarevistas.mackenzie.br/index.php/remef/article/view/1363/1065>. Acesso em: 18 jul. 2018.

BRASIL. Constituição (1988). Constituição da República Federativa do Brasil. Brasília, Disponível em: <http://www.planalto.gov.br/ccivil_03/constituicao/constituicao.htm>. Acesso em: 05 nov. 2017.

BRASIL. Lei n ${ }^{\circ}$ 9394, de 20 de dezembro de 1996. Diretrizes e Bases da Educação Nacional. Disponível em: <http://www.planalto.gov.br/ccivil_03/Leis/L9394.htm>. Acesso em: 05 nov. 2017.

BRASIL. Lei $\mathrm{N}^{\circ}$ 10.098, de 19 de março de 2000. Institui a Lei Brasileira de Inclusão da Pessoa com Deficiência. Brasília, DF, 6 jul. 2000. Disponível em: < http://www.planalto.gov.br/ccivil_03/_ato2015-2018/2015/lei/l13146.htm>. Acesso em: 01 jun. 2018.

BRASIL. Lei $\mathrm{N}^{\circ} 13.146$, de 6 de julho de 2015. Estabelece normas gerais e critérios básicos para a promoção da acessibilidade das pessoas portadores de deficiência ou com mobilidade reduzida. Brasília, DF, 19 dez. 2000. Disponível em: <http://www.planalto.gov.br/ccivil_03/leis/110098.htm>. Acesso em: 14 mai. 2018.

BRASIL. Ministério da Educação. Secretaria da Educação Básica. Fundamentos pedagógicos e estrutura geral da BNCC. Brasília, DF, 2017. Disponível em: http://basenacionalcomum.mec.gov.br/download-da-bncc>. Acesso em: jan. 2018.

CAMARGO, Brígido V.; JUSTO, Ana M.. IRAMUTEQ: Um software gratuito para análise de dados textuais. Temas em Psicologia, [s.1.], v. 21, n. 2, p.513-518, 2013. Associação Brasileira de Psicologia. http://dx.doi.org/10.9788/tp2013.2-16.

Convenção sobre os Direitos das Pessoas com Deficiência: Protocolo Facultativo à Convenção sobre os Direitos das Pessoas com Deficiência: Decreto Legislativo ${ }^{\circ}{ }^{\circ} 186$, de 09 de julho de 2008: Decreto $\mathrm{n}^{\circ}$ 6.949, de 25 de agosto de 2009. 4. ed., rev. e atual. Brasília: 
Secretaria de Direitos Humanos, 2010. 100p.

DAOLIO, Jocimar. A educação física escola como prática cultura: tensões e riscos. Revista Pensar a Prática, Goiânia, v.8, n.2, p. 215-226, 2005.

FÉLIX, Cristovão Alves. Relação Professor- Aluno nas aulas de Educação Física em Dois Riachos - AL: Realidade e perspectivas. 2012. 53 f. TCC (Graduação) - Curso de Curso de Licenciatura em Educação Física, Universidade de Brasília, Santana do Ipanema, 2012. Disponível em: <http://bdm.unb.br/bitstream/10483/5462/1/2012_CristovaoAlvesFelix.pdf>. Acesso em: 18 jul. 2018.

FREITAS, Hebrayn Bezerra. A importância do Espaço Físico e Materiais Pedagógicos para as aulas de Educação Física na Escola Pública do município de Unaí - MG. 2014. 36 f. TCC (Graduação) - Curso de Licenciada em Educação Física, Faculdade de Educação Física da Universidade de Brasília/df, Buritis, 2014. Disponível em: <http://bdm.unb.br/bitstream/10483/9615/1/2014_HebraynBezerraFreitas.pdf>. Acesso em: 18 jul. 2018.

FREIRE, Sofia. Um Olhar Sobre a Inclusão. Revista da Educação, Lisboa, v. 16, n. 1, p.5-20, $2008 . \quad$ Disponível em: <http://repositorio.ul.pt/bitstream/10451/5299/1/Um\%20olhar\%20sobre\%20a\%20Inclus\%C3\% A3o.pdf $>$. Acesso em: 17 jul. 2018.

FONSECA, João José Saraiva da. Metodologia da pesquisa científica. Fortaleza: UEC, 2002. $127 \mathrm{p}$.

GORGATTI, Márcia Greguol; ROSE JÚNIOR, Dante de. Percepções dos Professores Quanto à Inclusão de Alunos com Deficiência em Aulas de Educação Física. Movimento, Porto Alegre, v. $15, \quad$ n. 2, p.119-140, jan. 2009. Disponível em: <http://www.seer.ufrgs.br/index.php/Movimento/article/view/2971/5767>. Acesso em: 17 jul. 2018.

LAPLANE, Adriana Lia Friszman de. Condições para o ingresso e permanência de alunos com deficiência na escola. Cadernos Cedes, Campinas, v. 34, n. 96, p.191-205, ago. 2014. Disponível em: <http://www.scielo.br/pdf/ccedes/v34n93/0101-3262-ccedes-34-93-0191.pdf>. Acesso em: 26 jul. 2018.

LAPLANE, Adriana Lia Friszman de. O que os dados do censo escolar revelam sobre as barreiras à inclusão? Educação e Fronteiras On-line, Dourados, v. 5, n. 13, p.7-20, ago. 2015 Disponível em: <http://ojs.ufgd.edu.br/index.php/educacao/article/view/3762/2630>. Acesso em: 26 jul. 2018.

RIBEIRO, Sonia Maria. O esporte adaptado e a inclusão de alunos com deficiências nas aulas de educação física. 2009. 169 f. Tese (Doutorado) - Curso de Faculdade de Ciências Humanas Programa de Pós-graduação em Educação, Universidade Metodista de Piracicaba, Piracicaba, 2009. Disponível em: <http://www.unimep.br/phpg/bibdig/pdfs/2006/INAYIPCIURCT.pdf〉. Acesso em: 24 jul. 2018.

SILVA, Jean Piero Carvalho. A Satisfação em Aulas práticas de Atividade Física e Desportiva: Diferenças na satisfação de jovens com condição de deficiência intelectual e sem essa condição. 2014. 174 f. Tese (Mestrado) - Curso de Mestrado em Atividade Física, Especialização em Desporto Adaptado, Escola Superior de Educação do Instituto Politécnico de Castelo Branco, Castelo Branco, 2014.

SOUZA, Calixto Junior de. Entre o Adaptar e o Incluir: uma Abordagem Interdisciplinar da Disciplina de Educação Física Adaptada. Revista da Sobama, Marília, v. 15, n. 1, p.31-34, 2014. <http://www2.marilia.unesp.br/revistas/index.php/sobama/article/view/3800>. Acesso em: 17 jul. 2018. 
UNESCO. Declaração de Salamanca. Sobre Princípios, Políticas e Práticas na Área das Necessidades Educativas Especiais. Disponível em: <http://portal.mec.gov.br/seesp/arquivos/pdf/salamanca.pdf> Acesso em: 18 dez. 2018.

Artigo recebido em: 27/07/2018

Artigo aceito para publicação em: 18/09/2018 